\title{
Efeito do alecrim na defumação da carne de rã (Rana catesbeiana): características sensoriais, composição e rendimento
}

\author{
The effect of rosemary on the smoked frog meat (Rana catesbeiana): sensory \\ characteristics, composition, and carcass yield
}

\author{
Michele Ferreira ASSIS ${ }^{1}$, Maria Luiza Rodrigues Souza FRANCO ${ }^{1}$, Marta Verardino STÉFANI ${ }^{2}$, \\ Nilson Prado FRANCO ${ }^{1}$, Leandro Cesar GODOY ${ }^{3 *}$, Ana Cláudia OLIVEIRA ${ }^{1}$, \\ Jesui Vergilio VISENTAINER ${ }^{4}$, Adriana Ferreira SILVA 5 , Amanda Lilian Vieira $\mathrm{HOCH}^{1}$
}

\section{Resumo}

Este trabalho avaliou o efeito do alecrim na qualidade da carne de rã (Rana catesbeiana) defumada, por meio da análise das características sensoriais, da composição centesimal e do rendimento. Após o abate e a evisceração, as carcaças foram imersas em solução de salmoura (20\%) numa proporção de 2:1 (volume da salmoura/peso). Posteriormente, elas foram banhadas em azeite e defumadas a uma temperatura de 50 a $90{ }^{\circ} \mathrm{C}$. O delineamento experimental foi inteiramente casualizado, com 2 tratamentos $\left(\mathrm{T}_{1}=\right.$ Carcaça de rã defumada com alecrim; $\mathrm{T}_{2}=$ Carcaça de rã defumada sem alecrim) com 16 repetições. Na análise estatística, foi utilizado o programa SAEG 2004, com 5\% de significância. As carcaças defumadas apresentaram valores médios de proteína bruta (28,39\%), lipídios totais (5,13\%) e cinzas (2,79\%) superiores comparados aos das carcaças in natura $(23,41 ; 2,29$ e $0,85 \%)$. Não houve efeito significativo do alecrim na composição centesimal. A carcaça de rã defumada com alecrim apresentou melhor aceitação quanto ao aroma. Nas demais características sensoriais, a presença do alecrim não interferiu nos resultados. A carne de rã pode ser defumada com e sem alecrim, sem interferir na aceitabilidade do produto.

Palavras-chave: rã-touro; processamento; ervas aromáticas.

\begin{abstract}
This work studied the effect of rosemary on the quality of smoked frog meat (Rana catesbeiana) through the analysis of sensory characteristics, centesimal composition, and processing performance. The carcasses were immersed in a solution of brine (20\%), in the proportion of $2: 1$ (volume of brine/weight), soaked in olive oil and smoked at a temperature range from 50 to $90^{\circ} \mathrm{C}$. The experimental delineation was entirely casual with 2 treatments $\left(\mathrm{T}_{1}=\right.$ frog carcass with rosemary; $\mathrm{T}_{2}=$ frog carcass without rosemary) with 16 repetitions. For the statistical analysis, the SAEG 2004 program, with 5\% of significance was used. The smoked carcasses presented medium values of rude protein (28,39\%), total lipids $(5,13 \%)$, and ashes $(2,79 \%)$ comparatively higher than the values of the in natura carcasses $(23,41 ; 2,29$, and $0,85 \%)$. The rosemary did not affect the centesimal composition. The frog carcasses smoked with rosemary presented better acceptance concerning aroma. The rosemary did not affect the results of the other sensory characteristics. Frog meat can be smoked with and without rosemary since it does not interfere in the product acceptance.

Keywords: bull-frog; processing; aromatic herbs.
\end{abstract}

\section{Introdução}

No Brasil, a ranicultura firmou-se como uma atividade econômica na década de 80 . Desde então, ela vem passando por aperfeiçoamentos e, gradativamente, pode-se observar uma melhora significativa de produtividade. Atualmente, o País é considerado um dos maiores produtores mundiais, ficando atrás, apenas, da Indonésia e regiões circunvizinhas, locais onde as rãs são criadas de forma extensiva, em campos de arroz (Fundação Instituto de Pesca do Rio de Janeiro, 2006).

Praticamente, toda a produção brasileira - cerca de 400 ton./ ano - é absorvida pelo mercado interno. Contudo, de acordo com Ferreira (2006), se o País se preparar, terá condições de conquistar grande espaço no mercado externo.

No mercado interno, os produtos da ranicultura são a carne de rã fresca e/ou congelada, em carcaça inteira ou em partes, principalmente as coxas. Os demais produtos, como o dorso inteiro ou desossado e o dorso em pedaços são pouco explorados. Porém, estudos estão sendo realizados por institutos tecnológicos no que se refere à viabilidade de se aproveitar a carne do dorso da rã na formulação de patês, conservas, frogburger e emulsionados (MELLO; PESSANHA, 2006). Uma

Recebido para publicação em 14/11/2007

Aceito para publicação em 9/3/2008 (003015)

Departamento de Zootecnia, Universidade Estadual de Maringá - UEM, Av. Colombo, 5790, CEP 87020-900, Maringá - PR, Brasil

Departamento de Zootecnia, Centro de Aqüicultura da Unesp - CAUNESP, Faculdade de Ciências Agrárias e Veterinárias - FCAV, Universidade Estadual Paulista - UNESP, Jaboticabal - SP, Brasil

3 Programa de Pós-Graduação em Zootecnia, Universidade Federal do Rio Grande do Sul - UFRGS, Faculdade de Agronomia, Laboratório de Aquacultura,

Av. Bento Gonçalves 7712, CEP 91540-000, Porto Alegre - RS, Brasil, E-mail: godoyzoo@yahoo.com.br

${ }^{4}$ Departamento de Química, Universidade Estadual de Maringá - UEM, Av. Colombo, 5790, CEP 87020-900, Maringá - PR, Brasil

${ }_{5}$ Programa de Pós-Graduação em Ciências do Mar e Limnologia, Universidade Nacional Autônoma do México - UNAM, Sisal, Yucatán, México

${ }^{*}$ A quem a correspondência deve ser enviada 
outra alternativa para a comercialização da carne de rã seria a carne defumada.

A defumação de pescado é um método tradicional e tem como finalidade proporcionar ao produto características sensoriais desejáveis, tais como: a cor, o aroma, o sabor e a textura. Além disso, ela estende a vida útil do produto devido aos efeitos combinados da salga, da cocção, da secagem e da deposição de substâncias químicas bactericidas presentes na fumaça, isto é, os fenóis, os aldeídos e os ácidos orgânicos (SOUZA, 2003).

$\mathrm{O}$ alecrim (Rosmarinus officinalis) - dentre as especiarias com atividade antioxidante - tem sido objeto de vários estudos e apresenta características organolépticas desejadas pelo consumidor. Ele é classificado pelo Council of Europe (1981) como um aromatizante natural, podendo ser adicionado aos alimentos.

As inovações de cortes variados do pescado, a aplicação de ervas aromáticas e a defumação, associadas ao fato de os produtos estarem prontos ou semiprontos para o consumo, promove agregação de valor à cadeia produtiva da espécie em questão. Na tentativa de dar um tratamento especifico para o assunto - já que o Código Sanitário Federal não o contempla de forma específica (carne de rã defumada) - e, tendo em vista os aspectos mencionados anteriormente, o presente trabalho teve como objetivo avaliar o efeito do alecrim na defumação da carne de rã (Rana catesbeiana), por meio da análise das características sensoriais, da composição centesimal e do rendimento no processamento.

\section{Material e métodos}

\subsection{Animais e procedimento experimental}

Foram utilizadas 36 rãs com peso vivo médio de $235,87 \pm 30,53 \mathrm{~g}$, provenientes do Centro de Aquicultura da UNESP/Jaboticabal - SP. As rãs foram insensibilizadas com choque térmico (caixas isotérmicas com gelo moído e água, 1:1) e, após a pesagem, submetidas à evisceração e à lavagem. Distribuídas, aleatoriamente, em dois lotes, pesadas e identificadas. Em seguida, as carcaças foram imersas em uma solução de salmoura a 20\%, na proporção de 2:1 (volume da salmoura/peso), durante 15 minutos. Aquelas destinadas ao tratamento 1 foram incluídas na salmoura com o alecrim aproximadamente $30 \mathrm{~g}$ de ramos e folhas in natura, triturados em multiprocessador.

Após a salga, as carcaças foram banhadas em azeite de oliva, com o objetivo de proteger a superfície do produto do excesso de desidratação. Em seguida, foram drenadas e, posteriormente, colocadas na câmara de defumação para secagem parcial a uma temperatura de $50{ }^{\circ} \mathrm{C}$, durante 60 minutos. Decorrido esse período, iniciou-se a adição de fumaça. Foi utilizado um defumador artesanal de aço inox, com geração de fumaça externa à câmara de defumação. $\mathrm{O}$ combustível utilizado para produzir a fumaça foi a serragem de eucalipto rosa (Eucalyptus globulus Labill.). Para a manutenção da temperatura, utilizou-se gás de cozinha.
A temperatura da defumação iniciou-se $\operatorname{com} 50^{\circ} \mathrm{C}$ e atingiu $90^{\circ} \mathrm{C}$ na última hora de defumação, com acréscimo de $\pm 14^{\circ} \mathrm{C}$ a cada hora, totalizando 3 horas de exposição das carcaças à fumaça. O produto defumado, após a pesagem, foi disposto em bandejas de isopor com filme de plástico. As amostras para análise sensorial foram estocadas sob refrigeração $\left(5^{\circ} \mathrm{C}\right)$ por 24 horas, até o momento de sua realização. As demais amostras foram estocadas em freezer $\left(-18^{\circ} \mathrm{C}\right)$ até a realização da análise de composição centesimal.

\subsection{Rendimento e perdas durante o processamento}

Para a determinação do rendimento durante o processamento, foram utilizadas 33 carcaças, sendo este calculado, individualmente, em relação ao peso vivo de cada exemplar.

\subsection{Análises físico-químicas}

Foram realizadas análises da composição centesimal das carcaças de rã in natura e após a defumação em cada tratamento. As carcaças foram trituradas em multiprocessador até se obter uma polpa homogênea. Alíquotas desta polpa foram utilizadas para as determinações da composição centesimal.

Os teores de umidade e cinzas foram determinados conforme descrito em AOAC (1998), e os teores de proteína bruta determinados pelo método semimicro Kjeldahl, descrito por Silva (1981). Na extração dos lipídios totais, foi empregado o método de extração de gordura a quente, segundo Silva (1990).

\subsection{Análise sensorial}

Porções das carcaças de rã defumadas $( \pm 5 \mathrm{~g})$ foram avaliadas sensorialmente por um painel de 39 provadores não treinados, cerca de 24 horas após a defumação. As amostras foram padronizadas em relação ao corte a fim de se obter porções homogêneas - embaladas em papel alumínio - que foram oferecidas aos provadores.

Os provadores receberam as porções, de maneira aleatória, em pratos codificados, juntamente com uma ficha para a análise sensorial. Foram avaliados os atributos sabor, aroma, cor, textura, teor de sal, aparência e aceitação geral. Para tanto, utilizou-se uma ficha com escala hedônica de 9 pontos, com extremos 1 (desgostei muitíssimo) e 9 (gostei muitíssimo), de acordo com Dutcosky (1996).

\subsection{Delineamento experimental}

O delineamento experimental foi inteiramente casualizado, com dois tratamentos: $\mathrm{T}_{1}=$ Carcaça de rã defumada com presença de alecrim; $\mathrm{T}_{2}=$ Carcaça de rã defumada sem presença de alecrim, com 16 repetições por tratamento, sendo que a carcaça foi considerada a unidade experimental. Para a análise sensorial, foram 39 repetições no delineamento em blocos casualizados, em que cada provador foi considerado um bloco. 
Os resultados foram submetidos à análise de variância, e as médias foram comparadas pelo teste de Tukey, ao nível de 5\% de probabilidade, utilizando-se o programa SAEG 2004.

\section{Resultados e discussão}

\subsection{Rendimento e perdas durante o processamento}

Não houve diferença significativa $(\mathrm{p}>0,05)$ para o peso das carcaças de rã in natura, o que significa que as amostras utilizadas para cada tratamento estavam bem homogêneas (Tabela 1). As carcaças defumadas, independentemente da forma de processamento aplicada (com e sem alecrim), não apresentaram diferenças significativas quanto ao peso.

De acordo com Røra et al. (1998), as maiores perdas ocorrem durante o processo de defumação. Isto se deve à desidratação que ocorre na superfície do produto. Pode-se observar que a carcaça da rã, após o processo de defumação, evidencia regiões mais suculentas - como a coxa, que apresenta maior inserção muscular. Inversamente, a região do tronco apresenta menor quantidade de carne e, consequentemente, menor teor lipídico, favorecendo a perda de água nessa região. De acordo com Sigurgisladottir et al. (2000), os teores de gorduras também podem influenciar nas perdas durante o processo de defumação, ou seja, pescado com maior teor de gordura perde menor quantidade de água no processamento. A rã é considerada um pescado de baixo teor de lipídios, portanto, as perdas no processo de defumação são mais elevadas.

Independentemente do uso ou não do alecrim na defumação, não houve diferença significativa no rendimento da carcaça defumada, no que se refere às perdas ocorridas durante a defumação. As carcaças defumadas com alecrim apresentaram perdas de $55,51 \%$ e as defumadas sem alecrim 56,09\%.

Comparando os animais (machos e fêmeas), não houve diferença significativa $(\mathrm{p}>0,05)$ em todos os parâmetros analisados (Figura 1). Nesse intervalo de peso, ambos se encontravam homogêneos e esta característica se manteve com o processamento.

\subsection{Composição centesimal}

As carcaças da rã in natura apresentaram teor de umidade de $75 \%$. Esse valor encontra-se muito próximo ao encontrado por Nóbrega et al. (2007) para a coxa de rã in natura $(74,1 \%)$.
Lindau e Noll (1988), analisando a composição proximal da carcaça in natura, encontraram um teor de umidade de 83,68\%. Após o processo de defumação, com alecrim e sem alecrim, as carcaças não apresentaram diferenças significativas no teor de umidade, 60 e $63 \%$, respectivamente.

Com o processo de defumação, ocorre a desidratação e, consequentemente, a redução da quantidade de água, o que reflete na concentração de nutrientes. Isto pode ser observado na Tabela 2, em que os teores de proteína bruta, de lipídios totais e de cinzas das carcaças defumadas apresentam valores superiores em comparação aos das carcaças in natura. Os teores de proteína bruta $(23,40 \%)$ e lipídios totais $(2,27 \%)$ das carcaças in natura foram superiores aos relatados por Lindau e Noll (1988), 16,52 e $0,31 \%$, respectivamente.

Segundo Sigurgisladottir et al. (2000), a proteína bruta e os lipídios são mais elevados no pescado defumado do que no in natura. Principalmente, devido à perda excessiva de umidade, quando comparada à perda de lipídios e de proteínas solúveis, que decorre do processo de desidratação e lixiviação de lipídios do músculo durante a defumação. Desta maneira, o azeite de oliva foi utilizado com a finalidade de se evitar a desidratação excessiva do produto, proporcionando uma maior suculência

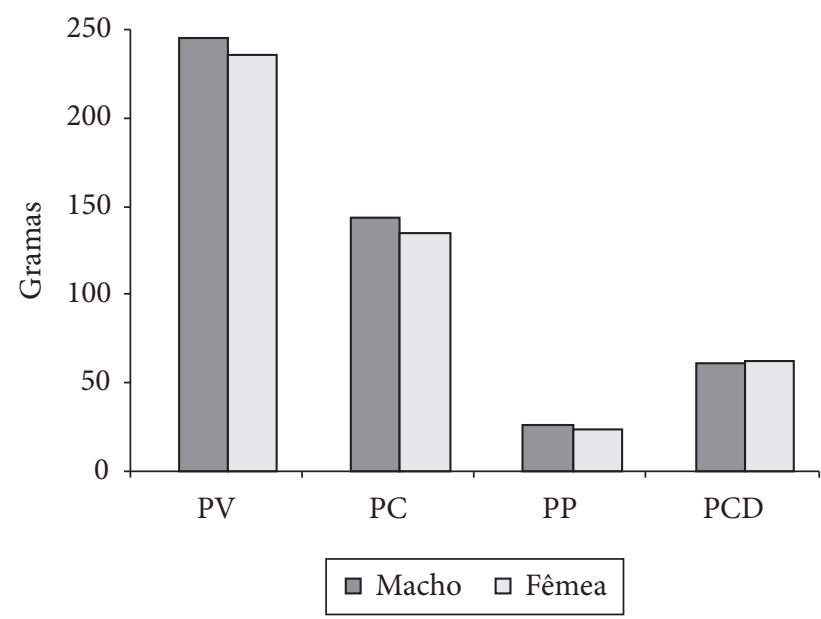

Figura 1. Valores médios de peso vivo (PV), peso da carcaça (PC), peso da pele (PP), e peso da carcaça defumada (PCD), de acordo com o sexo das rãs.

Tabela 1. Médias de peso vivo (PV), peso da carcaça (PC), peso da pele (PP), e rendimento de carcaça (RC) antes da defumação, peso da carcaça defumada (PCD), rendimento da carcaça defumada (RCD) e perdas na defumação (PND).

\begin{tabular}{cccccc}
\hline Fonte de variação & Defumada com alecrim & Defumada sem alecrim & Média geral & Teste $F$ & C.V (\%) \\
\hline PV (g) & $234,96 \pm 42,86$ & $236,73 \pm 22,27$ & $235,87 \pm 33,32$ & $0,001^{\text {ns }}$ & 14,44 \\
PC (g) & $133,59 \pm 22,49$ & $134,97 \pm 11,78$ & $134,30 \pm 16,52$ & $0,001^{\text {ns }}$ & 13,09 \\
PP (g) & $24,12 \pm 6,33$ & $24,43 \pm 2,90$ & $24,28 \pm 4,80$ & $0,000^{\text {ns }}$ & 19,95 \\
RC (\%) & $57,08 \pm 3,31$ & $57,08 \pm 1,94$ & $57,08 \pm 2,65$ & $0,027^{\text {ns }}$ & 4,70 \\
PCD (g) & $59,38 \pm 11,91$ & $59,07 \pm 9,68$ & $59,22 \pm 10,13$ & $0,003^{\text {ns }}$ & 17,66 \\
RCD (\%) & $25,38 \pm 2,92$ & $25,03 \pm 4,06$ & $25,20 \pm 3,50$ & $0,013^{\text {ns }}$ & 14,06 \\
PND (\%) & $55,51 \pm 4,69$ & $56,09 \pm 7,23$ & $55,81 \pm 6,04$ & $0,003^{\text {ns }}$ & 10,80 \\
\hline
\end{tabular}

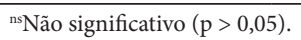


Tabela 2. Composição centesimal das carcaças de rãs in natura e defumadas com e sem alecrim.

\begin{tabular}{lcccc}
\hline \multicolumn{1}{c}{ Produto } & Umidade (\%) & Proteína bruta (\%) & Lipídios (\%) & Cinzas (\%) \\
\hline In natura & $75,00^{\mathrm{a}} \pm 0,39$ & $23,40^{\mathrm{a}} \pm 0,30$ & $2,27^{\mathrm{b}} \pm 0,06$ & $0,85^{\mathrm{b}} \pm 0,02$ \\
Defumada com alecrim & $60,00^{\mathrm{b}} \pm 3,53$ & $30,40^{\mathrm{a}} \pm 2,87$ & $4,97^{\mathrm{a}} \pm 0,88$ & $2,96^{\mathrm{a}} \pm 0,13$ \\
Defumada sem alecrim & $63,00^{\mathrm{b}} \pm 0,66$ & $26,37^{\mathrm{a}} \pm 1,24$ & $5,30^{\mathrm{a}} \pm 0,04$ & $2,60^{\mathrm{a}} \pm 0,00$ \\
\hline
\end{tabular}

Médias na mesma coluna com a mesma letra não diferem significativamente pelo Teste de Tukey $(\mathrm{p}>0,05)$.

Tabela 3. Médias das notas atribuídas, referentes às rãs defumadas com e sem alecrim.

\begin{tabular}{lcccc}
\hline Fonte de variação & Defumação com alecrim & Defumação sem alecrim & Teste $F$ & Coeficiente de variação (\%) \\
\hline Aroma & $7,95 \pm 0,86$ & $7,46 \pm 1,25$ & $4,15^{*}$ & 7,34 \\
Sabor & $8,00 \pm 1,15$ & $7,72 \pm 0,99$ & $1,17^{\text {ns }}$ & 7,07 \\
Aparência & $7,87 \pm 0,95$ & $7,64 \pm 1,11$ & $1,01^{\text {ns }}$ & 6,94 \\
Textura & $7,87 \pm 1,08$ & $7,62 \pm 1,16$ & $0,96^{\text {ns }}$ & 7,68 \\
Cor & $7,90 \pm 0,94$ & $7,56 \pm 1,29$ & $1,74^{\text {ns }}$ & 8,23 \\
Teor de sal & $7,90 \pm 1,27$ & $7,31 \pm 1,66$ & $3,06^{\text {ns }}$ & 10,90 \\
Aceitação geral & $8,15 \pm 0,84$ & $7,92 \pm 0,87$ & $1,38^{\text {ns }}$ & 5,45 \\
\hline
\end{tabular}

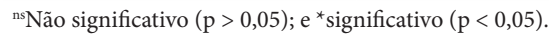

à carne defumada. Com isto, houve um acréscimo do teor de lipídios na composição centesimal das carcaças defumadas.

No que se refere ao teor de cinzas, além da desidratação ocorrida durante a defumação, há a influência do processo de salmouragem, que contribuiu para o aumento das cinzas devido à quantidade de sal agregado à superfície da carcaça. Como pôde ser observado neste experimento, o alecrim não exerceu influência significativa na composição centesimal das carcaças defumadas.

\subsection{Análise sensorial}

Os provadores notaram diferença significativa $(\mathrm{p}<0,05)$ na carne das rãs defumadas com alecrim, no atributo aroma. A média atribuída pelos provadores foi 7,95 para as carcaças defumadas com alecrim e 7,46 para as defumadas sem alecrim. Para as demais características sensoriais (Tabela 3), não houve diferença significativa $(\mathrm{p}>0,05)$.

Mesmo a rã sendo considerada um pescado magro pelo baixo teor de lipídios, e não sendo este indicado para defumação, a carne de rã defumada apresentou boa aceitação pelos provadores quanto às características sensoriais analisadas. Cabe ressaltar que estes são resultados preliminares de um trabalho pioneiro. Até o momento da finalização desta pesquisa, não se verificou a existência de nenhuma outra na literatura sobre a aplicação da defumação na carne de rã.

\section{Conclusões}

De acordo com os objetivos aqui propostos, a utilização do alecrim no processo de defumação da carne de rã não interferiu nas características sensoriais, melhorando apenas o aroma do produto defumado. Portanto, a carne de rã pode ser defumada com ou sem alecrim. Contudo, novas pesquisas são necessárias para que a carne de rã (in natura e defumada) possa ser contemplada de forma específica no Código Sanitário Federal e tornar-se, assim, mais conhecida pelo consumidor.

\section{Agradecimentos}

Ao Centro de Aquicultura da UNESP (CAUNESP/ Jaboticabal - SP), em especial à Prof ${ }^{\mathrm{a}}$. Dr ${ }^{\mathrm{a}}$. Marta Verardino De Stéfani, pela doação das rãs.

\section{Referências bibliográficas}

ASSOCIATION OF OFFICIAL ANALYTICAL CHEMISTS - AOAC. Official methods of analysis. 6 ed. Arlington, 1998.

COUNCIL OF EUROPE. Flavouring substances and natural sources of flavourings. 3 ed. Strasbourg: Maisonneuve, 1981.

DUTCOSKY, S. D. Análise sensorial de alimentos. Curitiba: Champagnat, 1996.

FERREIRA, C. M. Ranicultura. Disponível em: $<$ http://www.aquicultura. br/ranicultura.htm>. Acesso em: 28 Outubro 2006.

Fundação Instituto de Pesca do Estado do Rio de Janeiro. Ranicultura: a ranicultura no Estado do Rio de Janeiro. 2006. Disponível em: $<$ http:// www.fiperj.rj.gov.br/ranicu.html>. Acesso em: 28 Outubro 2006.

LINDAU, C. F.; NOLL, I. B. Determinação do valor nutritivo da carne de rã. In: ENCONTRO NACIONAL DE RANICULTURA, 6, 1988. Anais... Rio de Janeiro: Associação dos Ranicultores do Estado do Rio de Janeiro, 1988. p. 43-50.

MELLO, S. C. R. P.; PESSANHA, L. S. Avaliação bacteriológica e físicoquímica da polpa de dorso de rã obtida por separação mecânica. Brazilian Journal of Food Technology, v. 9, n. 1, p. 39-48, jan./mar. 2006.

NÓBREGA, I. C. C. et al. Volatile constituents of cooked bullforg (Rana catesbeiana) legs. Food Chemistry, v. 102, n. 4, p-186-191, 2007.

RØRA, A. M. B. et al. Process yield, colour and sensory quality of smoked Atlantic salmon (Salmo salar) in relation to raw material characteristics. Food Research International, v. 31, n. 8, p. 601-609, 1998.

SIGURGISLADOTTIR, S. et al. Effects of different salting and smoking processes on the microstructure, the texture and yield of Atlantic salmon (Salmo salar) fillets. Food Research International, v. 33, n. 10 , p. $847-855,2000$.

SILVA, D. J. Análise de alimentos (Métodos Químicos e Biológicos). Viçosa: Imprensa Universitária da UFV, 1981.

SILVA, D. J. Análise de Alimentos: (Métodos Químicos e Biológicos). 2 ed. Viçosa: Universidade Federal de Viçosa, 1990.

SOUZA, M. L. R. Processamento do filé e da pele da tilápia do Nilo (Oreochromis niloticus): aspectos tecnológicos, composição centesimal, rendimento, vida útil do filé defumado e teste de resistência da pele curtida. Jaboticabal, 2003. $169 \mathrm{f}$. Tese (Doutorado em Zootecnia) - Centro de Aqüicultura, Universidade Estadual Paulista - UNESP. 